\title{
Lipomatous Hamartoma: A Rare Cause for Endobronchial Obstruction
}

\section{Gayathri Devi HJ*}

Department of chest diseases, MS Ramaiah medical college, Bangalore, India

\author{
Abstract \\ Benign tumours of the tracheobronchial tree are quite rare. Hamartoma of the lung is the most common benign \\ tumour. We report a rare case of lipomatous hamartoma causing endobronchial obstruction in a 65 year old male.
}

Keywords: Endobronchial; Hamartoma; Lipomatous

\section{Introduction}

Hamartomas are the commonest benign tumors of the lung. Incidence varies between $0.025 \%$ and $0.32 \%$ [1]. They are located commonly in the peripheral part of the lung and rarely in the endobronchial region. When the predominant component is fatty tissue they are called as lipomatous hamartoma. Endobronchial Hamartoma (EH) can cause obstruction of the airways leading to distal lung damage. We report a case of endobronchial lipomatous hamartoma in a 65 year old male who presented to us for the evaluation of chronic cough.

\section{Case Report}

A 65- year old male, presented with cough of one month duration and breathlessness on exertion of one week duration. At the onset, he had fever for a week which subsided after taking a course of antibiotics from a local hospital. He had history of smoking 1-2 cigarettes per week for 40 years. He was a hypertensive on regular medication. His physical examination was normal.

Routine laboratory work-up was normal except for a raised erythrocyte sedimentation rate of $95 \mathrm{~mm}$. Sputum for acid fast bacilli

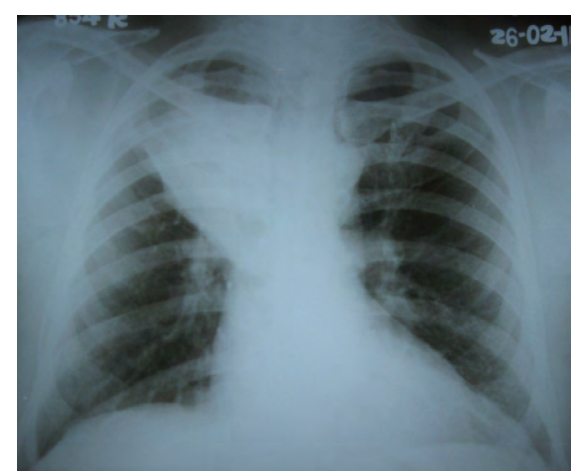

Figure 1: Chest x-ray showed a dense homogeneous opacity in the right upper zone.

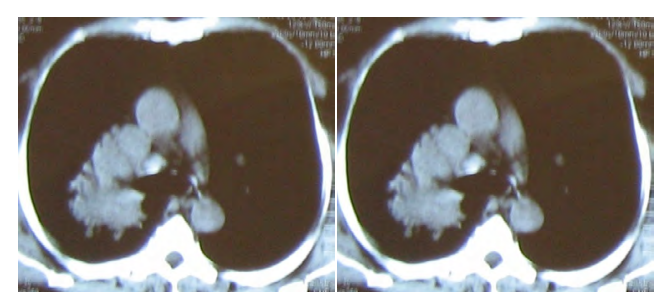

Figure 2: Contrast enhanced computerized tomography of the thorax showing soft tissue density mass with irregular margins in the right upper lobe with obliteration of the lumen of right upper lobe bronchus. was negative. His chest $\mathrm{x}$-ray showed a dense homogeneous opacity in the right upper zone consistent with collapse/consolidation (Figure 1). Contrast enhanced computerized tomography of the thorax revealed soft tissue density mass with irregular margins in the right upper lobe with obliteration of the lumen of right upper lobe bronchus. There was no mediastinal lymphadenopathy (Figure 2A and 2B). Our probable diagnosis was bronchogenic carcinoma considering the age of the patient. Fiberoptic bronchoscopy was done and it revealed a polypoidal lesion in the right upper lobe bronchus (Figure 3). The lesion had a smooth surface and there was no purulent discharge from the lumen. Brochoalveolar lavage fluid was negative for acid fast bacilli and malignant cells. Culture did not yield any growth. Direct biopsies were taken from the lesion and histopatholgy examination showed tissue lined by ciliated columnar epithelium. Subepithelium consisted of fibrocollagenous tissue and predominantly mature fat cells suggestive of lipomatous hamartoma (Figure 4 and 5).

On follow-up examination, he was asymptomatic and chest X-ray showed complete resolution of the opacity (Figure 6). Radiological improvement is an indirect evidence of spontaneous regression of the lesion. The reason could be due to hypoxia that occurs in the core of the tumour, leading to necrosis of tumour cells causing them to implode [2]. Our patient refused repeat bronchoscopy since he was asymptomatic. He continued to be asymptomatic two years post-bronchoscopy.

\section{Discussion}

Benign tumors represent less than $1 \%$ of all lung neoplasms. Among the benign tumours, hamartomas are the most common [3]. Albrecht in 1904 coined the term "Hamartoma" to describe tumor-like malformations which were considered to be developmental anomalies. Hamartomas are now considered as true neoplasms rather than developmental anomalies. Their rarity in childhood and appearance in adult life is suggestive of a neoplastic lesion. Several cytogenetic studies have identified recombination of chromosomal bands $6 \mathrm{p} 21$ and $14 \mathrm{q} 24$ supporting the neoplastic nature of the lesion [4]. Hamartomas are composed of an abnormal mixture of mesenchymal and epithelial elements like cartilage, bone, fat, and fibrous tissues [5]. Hamartomas are divided into intraparenchymal and endobronchial types depending

*Corresponding author: Gayathri Devi HJ, Associate professor, Department of chest diseases, MS Ramaiah medical college, Bangalore, India, Tel: +918040502000, ext-3094; E-mail: gayathrijoshy@gmail.com

Received August 25, 2013; Accepted October 25, 2013; Published October 28 2013

Citation: Gayathri Devi HJ (2013) Lipomatous Hamartoma: A Rare Cause for Endobronchial Obstruction. J Pulmon Resp Med S14: 007. doi:10.4172/2161105X.S14-007

Copyright: (c) 2013 Gayathri Devi HJ. This is an open-access article distributed under the terms of the Creative Commons Attribution License, which permits unrestricted use, distribution, and reproduction in any medium, provided the original author and source are credited. 
Citation: Gayathri Devi HJ (2013) Lipomatous Hamartoma: A Rare Cause for Endobronchial Obstruction. J Pulmon Resp Med S14: 007. doi:10.4172/2161-105X.S14-007

Page 2 of 3

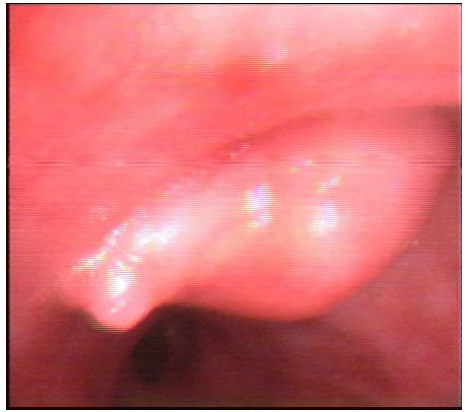

Figure 3: Fiberoptic bronchoscopy showing a polypoidal lesion in the right upper lobe bronchus.

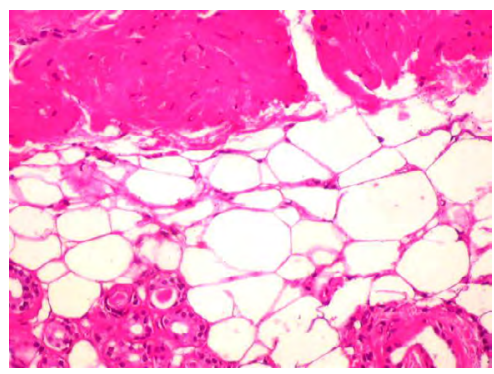

Figure 4: Aggregates of adipocytes with surrounding fibromuscular tissue.

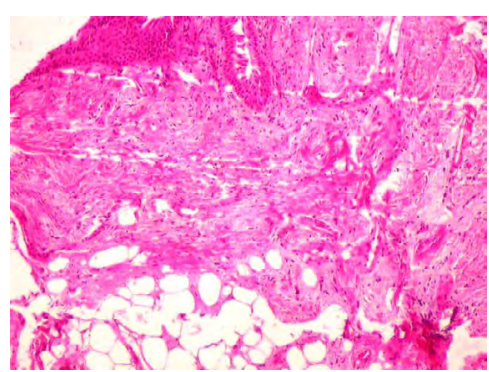

Figure 5: Aggregates of adipocytes with surrounding fibromuscular tissue, surface show bronchoepithelial lining.

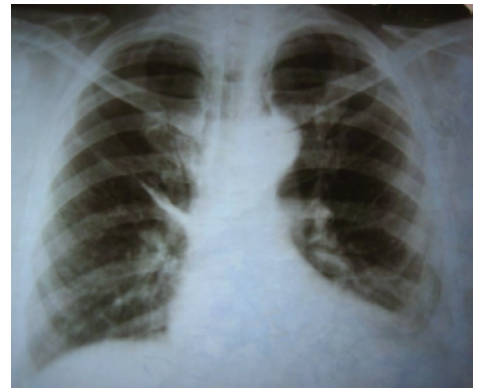

Figure 6: Chest X-ray showing resolution of the right upper zone opacity.

on the location of the lesion. Hamartomas present usually as intraparenchymal nodules in the periphery of the lung.

Endobronchial hamartomas are rare. Gjevre et al have analyzed 215 cases of hamartomas and only $1.4 \%$ were located in the endobronchial region [6]. Typically, endobronchial hamartomas contain more fat than parenchymal hamartomas [7]. When the predominant component is fatty tissue, they are called as lipomatous hamartoma [5]. Peak incidence of hamartoma is in the sixth or seventh decade. Hamartomas are more frequent in males than females. Intraparenchymal hamartomas are incidentally found as solitary nodules. They can present in any part of the lung near the pleura. Characteristic popcorn calcification is seen in $10 \%$ of the cases. Endobronchial hamartomas usually present with symptoms of airway obstruction. Endobronchial obstruction may lead to recurrent pneumonia or atelectasis. Symptoms of EH include cough, haemoptysis, wheezing, chest pain, and fever. EH appears as a polypoidal or pedunculated mass with a smooth surface on bronchoscopic examination. Multi slice CT (MSCT) is highly specific and sensitive for endobronchial neoplasms with fat content like endobronchial lipoma or hamartoma [8].

Lipomas are well encapsulated, contain lobules of mature adipose tissue, and are lined by respiratory epithelium. Differentiating endobronchial lipomatous hamartoma from lipoma is of little interest, since both are benign tumors of mesenchymal origin [9]. Benign endobronchial tumors can cause post obstructive lung damage. Distal lung damage can be prevented by early resection of the tumor.

Treatment includes surgical versus bronchoscopic resection [10]. Endobronchial hamartomas are benign and have a very low risk of malignancy. The treatment of choice is endoscopic laser resection if there is no irreversible damage to the distal lung [11]. Laser resection using Neodymium-yttrium aluminium garnet (Nd:YAG) and diode laser has been described. Rigid and flexible bronchoscope can be used for the procedure [12]. Resection surgery (pneumonectomy, lobectomy and bronchotomy) is the treatment of choice if there is significant distal lung damage.

The management of EHs must be individualized based on the characteristics of each patient [13].

\section{Conclusion}

In cases of endobronchial obstruction, rare cause like hamartoma has to be kept in mind as reported here. It is also important to differentiate benign from malignant endobronchial tumours.

\section{References}

1. Murray J, Kielkowski D, Leiman G (1991) The prevalence and age distribution of peripheral pulmonary hamartomas in adult males. An autopsy-based study. S Afr Med J 79: 247-249.

2. Oluwole O, Samaila M (2009) Spontaneous Tumour regression. Int J Patho 8: 18.

3. Mondello B, Lentini S, Buda C, Monaco F, Familiari D, et al. (2011) Giant endobronchial hamartoma resected by fiberoptic bronchoscopy electrosurgical snaring. J Cardiothorac Surg 6: 97.

4. Lien YC, Hsu HS, Li WY, Wu YC, Hsu WH, et al. (2004) Pulmonary hamartoma J Chin Med Assoc 67: 21-26.

5. Lakhotia S, Dewan RK (2008) Endobronchial lipomatous hamartoma: A rare cause of bronchial occlusion with destroyed lung. Indian Journal of Thoracic and Cardiovascular Surgery 24: 201-202.

6. Gjevre JA, Myers JL, Prakash UB (1996) Pulmonary hamartomas. Mayo Clin Proc 71: 14-20.

7. Gaerte SC, Meyer CA, Winer-Muram HT, Tarver RD, Conces DJ Jr (2002) Fatcontaining lesions of the chest. Radiographics $22 \mathrm{Spec}$ No: S61-78.

8. Ko JM, Jung JI, Park SH, Lee KY, Chung MH, et al. (2006) Benign tumors of the tracheobronchial tree: CT-pathologic correlation. AJR Am J Roentgenol 186: $1304-1313$.

9. Cao D, Sun Y, Yang S (2011) Endobronchial lipoma: an unusual cause of bronchial obstruction. Case Rep Med 2011: 939808. 
Citation: Gayathri Devi HJ (2013) Lipomatous Hamartoma: A Rare Cause for Endobronchial Obstruction. J Pulmon Resp Med S14: 007. doi:10.4172/2161-105X.S14-007

10. Schneider F, Winter H, Schwarz F, Niederhagen M, Arias-Herrera V, et al (2012) Endobronchial lipomatous hamartoma: an incidental finding in a patient with atrial fibrillation-a case report. Case Rep Med 2012: 897581.

11. Cheu HW, Grishkin BA, Linville WK (1993) Endobronchial hamartoma treated by bronchoscopic excision. South Med J 86: 1164-1165.
12. Rai SP, Patil AP, Saxena P, Kaur A (2010) Laser resection of endobronchial hamartoma via fiberoptic bronchoscopy. Lung India 27: 170-172.

13. Cosío BG, Villena V, Echave-Sustaeta J, de Miguel E, Alfaro J, et al. (2002) Endobronchial hamartoma. Chest 122: 202-205.

This article was originally published in a special issue, Pulmonology- Case Reportshandled by Editor(s). Dr. Anna Blumental-Perry, Memorial University Medical Center, USA. Dr. Bradley Allen Maron, Brigham and Women's Hospital, USA. 